\title{
Common variable immune deficiency, central diabetes insipidus, and anemia
}

\author{
MARTA BALEVA ${ }^{l}$, SPASKA LESICHKOVA ${ }^{l}$, NEVENA GESHEVA ${ }^{l}$, SNEJINA MIHAILOVA ${ }^{1,2}$, \\ VANYA GEROVA ${ }^{2,3}$, BORISLAV VLADIMIROV ${ }^{2,3}$, PLAMEN PENCHEV $V^{2,3}$, \\ MILENA NIKOLOVA-VLAHOVA ${ }^{2,4}$, ELISSAVETA NAUMOVA ${ }^{1,2}$
}

${ }^{1}$ Clinic of Clinical Immunology and Stem Cell Bank, University Hospital Alexandrovska, Expert Centre on Rare Diseases Primary Immune Deficiencies, Sofia, Bulgaria

${ }^{2}$ Medical University, Sofia, Bulgaria

${ }^{3}$ Clinic of Gastroenterology, University Hospital Queen Joanna, Sofia, Bulgaria

${ }^{4}$ Clinic of Nephrology, University Hospital St. Ivan Rilski, Sofia, Bulgaria

\begin{abstract}
Common variable immune deficiency (CVID) accounts for approximately $20 \%$ of all cases of primary immune deficiencies, and is characterized by low serum levels of $\operatorname{Ig} G, \operatorname{IgA}$, and/or IgM. The diagnosis is usually made between 20 and 40 years of age, sometimes earlier. CVID patients are divided into two major groups based on complications observed: 1 group consists of patients with predominant infections, and 2 group includes patients with inflammatory and/or hematological complications, such as lymphadenopathy, splenomegaly, autoimmune cytopenia, enteropathy, and/or granulomatous conditions. The most prevalent gastrointestinal symptom is transitory or persistent diarrhea. Central diabetes insipidus (CDI) is a rare disease associated with decreased synthesis or release of antidiuretic hormone that leads to an excessive production of diluted urine (polyuria). Different factors can lead to the development of CDI, including autoantibodies to arginine vasopressin-producing cells. Celiac disease is an autoimmune condition affecting small intestine in genetically predisposed individuals, which can be associated with endocrinopathies. Here, we describe a patient with CVID, CDI, gluten-sensitive diarrhea, and anemia of combined type (thalassemia minor and B12-deficiency anemia).
\end{abstract}

Key words: CVID, central diabetes insipidus, anemia, celiac disease, autoimmunity, diagnosis, IVIG.

(Cent Eur J Immunol 2020; 45 (3): 351-354)

\section{Introduction}

Common variable immune deficiency (CVID) accounts for approximately $20 \%$ of all cases of primary immune deficiencies [1]. It is characterized by marked decrease of IgG serum levels $(<2$ SD below the mean for age), measured at least twice and other criteria according to revised 2017 ESID diagnostic criteria for CVID [2]. The prevalence of CVID in general population ranges from $1: 25,000$ to $1: 50,000$ [3]. The diagnosis is usually made between 20 and 40 years of age, sometimes earlier. CVID patients are divided into two major groups based on complications observed: 1 group consists of patients with predominant infections, and 2 group includes patients with inflammatory and/or hematological complications, such as lymphadenopathy, splenomegaly, autoimmune cytopenia, enteropathy, and/or granulomatous conditions [3]. The most prevalent gastrointestinal symptom is transitory or persistent diarrhea $[4,5]$. Several gene mutations have been detected in CVID patients, such as ICOS [6], CD19
[7], CD81 [8], CD21 [9], CD20 [10], LRBA [11], PLCG2 [12], TWEAK [13], and NFKB2 [14].

Central diabetes insipid (CDI) is a rare disease associated with decreased synthesis from hypothalamus and/or decreased release from posterior pituitary of antidiuretic hormone (arginine vasopressin) that leads to an excessive production of diluted urine (polyuria). Different factors can lead to the development of CDI, including autoantibodies to the arginine vasopressin-producing cells (i.e., autoimmune mechanisms) [15].

Celiac disease is an autoimmune disorder affecting small intestine in genetically predisposed individuals. The disease manifests with diarrhea, abdominal distension and pain, malabsorption, loss of appetite and, in small children, failure to thrive when gluten-containing products are ingested. These symptoms usually appear at young age (when gluten is introduced into the diet) and ameliorate when gluten-free diet is undertaken, but can appear at much older age, even in adults. Celiac disease can be 
associated with other autoimmune disease, including autoimmune endocrinopathies $[16,17]$.

Here, we describe a patient with CVID, CDI, glutensensitive diarrhea, and anemia of combined type (thalassemia minor and B12-deficiency anemia).

\section{Clinical case}

A 45-years-old male patient was admitted to the Clinic of Clinical Immunology in December 2016 with continual and resistant to treatment diarrhea, fatigue, edema on the legs, and weight loss. The patient had extremely low serum immunoglobulin levels, such as IgG $0.67 \mathrm{~g} / \mathrm{l}, \mathrm{IgA}$ $0.02 \mathrm{~g} / \mathrm{l}$, and $\mathrm{IgM} 0.156 \mathrm{~g} / \mathrm{l}$. The patient reported having diarrhea episodes since 2000, which were difficult to treat, and gradually, fatigue, edema on the legs, and weight loss appeared.

In 2012, upper endoscopy was normal and biopsies of the fundus, antrum, bulb, and second portion of duodenum were performed. Histopathological examination indicated atrophic gastritis and chronic duodenitis with partial to subtotal villous atrophy (Marsh grade, 3A-3B). The later histological finding suggested gluten-sensitive enteropathy (celiac disease), but celiac serology (IgA and IgG anti-transglutaminase antibody) was negative. A colonoscopy with ileoscopy was also performed. No lesions were observed in the colon, but the terminal ileum presented with severe edema, and nodular appearance compatible with nodular lymphoid hyperplasia was confirmed by histopathological examination. A gluten-free diet was initiated. Six months later, diarrhea disappeared, and weight gain was observed.

In 2010, the patient had an episode of polyuria, with up to $10-121$ in 24 hours. Subsequently, he underwent water deprivation test and was diagnosed with CDI, with desmopressin $0.2 \mathrm{mg}$ two times a day prescribed, with excellent effect on polyuria. In 2013, the patient had a deep vein thrombosis of right leg and was treated with anti-vitamin K agent (acenocumarol) for 3 years. The patient reported episodes of severe and protracted infections in the past, including panaritium of a finger, after minimal trauma that required oral clindamycin treatment one year before the current admission. Moreover, the patient has thalassemia minor and family history of type 1 diabetes mellitus (mother).

Physical examination at the admission revealed mildly impaired general condition, body weight of $70 \mathrm{~kg}$, heart rate of $74 \mathrm{bpm}$, and edema on the left shank. The rest of physical examination, including the thyroid gland, respiratory, cardio-vascular systems, and abdomen was within range.
Clinical laboratory investigations at the admission showed normal levels of blood glucose, liver enzymes, bilirubin, urea, creatinine, electrolytes, erythrocyte sedimentation rate (ESR), C-reactive protein (CRP), white blood cells, platelet count, TSH, fT4, LH, FSH, testosterone, cortisol ( $8 \mathrm{~h}$ and $23 \mathrm{~h}$ ), and negative HIV, HBV, HCV, EBV serum markers. The patient had low hemoglobin (Hb) level: $92 \mathrm{~g} / 1$ (normal range, 135-180 g/l), low erythrocytes: $3.58 \mathrm{~g} / \mathrm{l}$ (normal range, 4.4-5.9 G/l), low iron: $8 \mu \mathrm{mol} / \mathrm{l}$ (normal range, $11-28 \mu \mathrm{mol} / \mathrm{l}$ ), total iron-binding capacity (TIBC): 49 (normal range, 44.8-80.6), increased $\mathrm{HbA} 2: 4.8 \%$ (normal range, 1.75-3.25\%), HbF: 0\% (normal range, $<1 \%$ ), decreased hematocrit: 0.28 (normal range, 0.4-0.53), mean corpuscular volume (MCV): 79 (normal range, 82-96), $\mathrm{MCH}: 25$ (normal range, 27-33), ferritin: 51 (normal range, 30-400), low albumin: $35 \mathrm{~g} / \mathrm{l}$ (normal range, 35-53), low total protein levels: $46 \mathrm{~g} / \mathrm{l}$ (normal range, 6083), and low vitamin B12: 88 pmol/l (normal range, 141$489 \mathrm{pmol} / \mathrm{l})$. The erythrocyte morphology showed mixed anisocytosis, marked hypochromia, target cells, and several poikilocytes.

The patient received one blood transfusion of red blood cells mass. Due to proven vitamin B12 deficiency, intramuscular substitution and temporary oral iron substitution were started. Desmopressin and gluten-free diet were continued. Due to the presence of hypogammaglobulinemia, the patient was started on substitution with intravenous immunoglobulins (IVIG), $10 \mathrm{~g} / \mathrm{month}$. After the second month, the dose was increased to $15 \mathrm{~g} /$ month and after month 4 , the dose was $22.5 \mathrm{~g} /$ month. It was assumed that the dose of IVIG was lower than optimal due to logistic and financial limitations. However, the level of IgG after IVIG infusions reached $3.65 \mathrm{~g} / \mathrm{l}$, and immediate SCIG substitution treatment with a dose of $141.4 \mathrm{mg} / \mathrm{kg} /$ week was applied, which resulted in significantly improved IgG level to nearly $10 \mathrm{~g} / \mathrm{l}$. We observed subsiding of edema and a reduction of diuresis to 2-3 1 in 24 hours. The patient was diarrhea-free, and body weight stabilized $(70 \mathrm{~kg})$.

Table 1 shows the changes in serum IgG levels during the treatment with IVIG.

At the first admission into our department, the patient presented with CD3+ cells of $78 \%$ (2808 cells/ $\mu \mathrm{l})$, with $8 \%$ of CD3+CD4+ cells $(288$ cells $/ \mu \mathrm{l})$, and $70 \%$ of $\mathrm{CD} 3+\mathrm{CD} 8+$ cells $(2520$ cells $/ \mu \mathrm{l})$. B lymphocytes were $4 \%(144$ cells $/ \mu 1)$ and CD3-CD16+CD56+ cells were $13 \%$ (468 cells $/ \mu 1)$. One year later, $\mathrm{T}$ cells dropped to $47 \%(1772$ cells/ $\mu \mathrm{l})$ with higher markers of activation $(\mathrm{CD} 3+\mathrm{DR}+19 \%), \mathrm{CD} 3+\mathrm{CD} 4+$ cells became lower: $5 \%(189$ cells $/ \mu \mathrm{l}), \mathrm{CD} 3+\mathrm{CD} 8+$ cells decreased to $48 \%$

Table 1. Dynamics of serum IgG levels during intravenous immunoglobulins treatment

\begin{tabular}{|c|c|c|c|c|c|c|c|}
\hline Marker & $\begin{array}{c}\text { December 23, } \\
2016\end{array}$ & $\begin{array}{c}\text { February 6, } \\
2017\end{array}$ & $\begin{array}{c}\text { March 20, } \\
2017\end{array}$ & June 23, 2017 & $\begin{array}{c}\text { July 28, } \\
2017\end{array}$ & $\begin{array}{c}\text { October 5, } \\
2017\end{array}$ & $\begin{array}{c}\text { Reference } \\
\text { range }\end{array}$ \\
\hline $\mathrm{IgG}, \mathrm{g} / 1$ & 0.67 & 1.977 & 2.844 & 2.739 & 3.657 & 3.653 & $5.4-16.1$ \\
\hline
\end{tabular}


(1819 cells/ $\mu \mathrm{l})$. B cells were at about the same level: $3 \%$ (113 cells/ $\mu \mathrm{l}$ ) and NK cells went up to $49 \%$ (1847 cells/ $\mu \mathrm{l})$. During this period, the patient presented with leukocytosis and absolute lymphocytes (Ly) $3.77 \times 10^{3} \mathrm{cells} / \mu \mathrm{l}$. After three months, the changes in the percentage distribution of cell subsets persisted; however, the absolute Ly were $1.66 \times 10^{3} \mathrm{cells} / \mu \mathrm{l}$. Possibilities of combined immune deficiency-CID were discussed, and functional testing of $\mathrm{T}$ cells was performed. The results showed normal PHA and CD3/CD28 T cell response. Additionally, the percentage of nadve CD4+T cells in the first and follow-up measurements was also evaluated and was 18-14-19\%. Based on the above and due to the absence of other causes of hypogammaglobulinemia, we accepted the diagnosis CVID in our patient.

\section{Discussion}

Overall, 20\% of CVID patients are known to develop autoimmune diseases, including Hashimoto thyroiditis, Addison's disease, type 1 diabetes mellitus, autoimmune hemolytic anemia, autoimmune thrombocytopenia, B12-deficient anemia due to atrophic gastritis, etc. [18]. CVID can be associated with celiac disease but in such cases, the latter remains "seronegative" and other disease markers are crucial for diagnosis, such as villous blunting/atrophy, intraepithelial lymphocytes count, and positive gluten-challenge test [19]. In the literature, we found only one report of CVID with central diabetes insipidus in a 37-year-old male patient with 10 years of history of thirst, polyuria, and nocturia, treated with vasopressin (DDAVP) [20]. In his childhood, the patient had frequent respiratory and gastrointestinal infections. Eight years before the manifestation of CDI, he was diagnosed with Hodgkin's disease IA stage (cervical lymph nodes) and underwent polychemotherapy with 6 cycles with adriamycin, bleomycin, vinblastine, and dacarbazine (ABVD), followed by X-ray therapy in the affected zone (total dose, $30 \mathrm{~Gy}$ ). The patient had no complications, and complete disease remission was reached. Several years later, on a routine prophylactic investigation, low serum immunoglobulin levels ( $\operatorname{IgG}, \operatorname{IgA}$ and $\operatorname{IgM}$ ) were detected in the lack of vaccine response and low peripheral memory B cells. Additionally, his mother suffered from rheumatoid arthritis.

Younes and Second [21] described a case of 12-yearold girl with panhypopituitarism, with low growth hormone levels and without CDI, CVID, and episodes of adrenal crisis triggered by pneumonia. Moreover, cases of CVID in association with low growth hormone levels and anti-pituitary antibodies [22] as well as CVID with adrenocorticotropic hormone deficiency [23] have been described.

Our patient was diagnosed with CVID at the age of 45 , when serum immunoglobulin levels were investigated for other reason. He reported having not very frequent but severe and protracted viral and bacterial infections.
During the 10-month period of treatment and observation, the patient received IVIG, 10 to $20 \mathrm{~g}$ intravenously, and IgG level increased from 0.67 to $3.65 \mathrm{~g} / \mathrm{l}$. We considered the possibility of immune deficiency due to regulatory $\mathrm{T}$ cell defects. However, our patient did not fulfill even a part of clinical and laboratory features of well-studied and described syndromes of this category. It is assumed that future investigation of such cases needs an evaluation of Tregs and some cytokine responses. The genetic testing is absolutely necessary to define eventual defect (or new one) in these unusual cases [2].

Our patient was diagnosed with CDI in 2010 and for 7 years remained on desmopressin treatment with good therapeutic response. The autoimmune genesis of this condition remains disputable. Pivonello et al. [15] observed a possible autoimmune genesis of CDI and described autoantibodies directed against arginine vasopressin secreting cells. Due to the low immunoglobulin level in our patient, it would be difficult, even impossible, to detect such autoantibodies. Moreover, our patient suffered from gluten intolerance (i.e., positive gluten-challenge test and improvement of diarrhea when on gluten-free diet), with diarrhea and positive histological findings pointing at celiac disease (subtotal villous atrophy) with negative serological markers. In patients with low serum immunoglobulin levels, the serological markers are not reliable diagnostic instruments, and clinical and histological findings should be the targets of diagnosis [19].

Our patient's anemia is of complex origin. On the one hand, the histological data from upper endoscopy revealed atrophic gastritis, chronic duodenitis with partial to subtotal villous atrophy, and laboratory data showed vitamin B12 deficiency. On the other hand, the patient had thalassemia minor, with $\mathrm{Hb} \mathrm{A} 2$ of $4.8 \%$ (normal, 1.75-3.25), HbF of $0 \%$ (normal $<1 \%$ ). Vitamin B12-deficient anemia should be suspected in CVID patients, especially in the presence of neurological and gastrointestinal complications [24]. Moreover, autoimmune hemolytic anemia should be suspected. Besides B12 and iron supplementation, when hemoglobin levels are extremely low, blood transfusion should be performed. In our patient, one erythrocytes transfusion due to extremely low hemoglobin level was done.

As to the accessible literature, the described patient is the second case in the literature with CVID and CDI [20]. However, our patient differs in many ways from the patient described by Megías et al. [20], who presented with more frequent and more severe infections in the past and had been treated for Hodgkin's disease. Moreover, low serum immunoglobulin levels were detected several years after complete remission from oncological disease. In our patient, the leading symptom was diarrhea, which was classified as gluten-sensitive enteropathy (celiac disease), based on endoscopic and histological findings and gluten-challenge test (including excellent clinical response to gluten-free diet). Both patients had a family history of 
autoimmune disease, including type 1 diabetes in our patient and rheumatoid arthritis in the other case, and in both patients, the carrier of autoimmune disease was the mother. It is well-known that autoimmune diseases are found with higher prevalence among the members of one family. The autoimmune diseases in our patient were gluten-sensitive enteropathy, vitamin B12-deficiency anemia with atrophic gastritis, and CDI most probably with autoimmune genesis. We have no serological data for celiac disease because the patient had extremely low serum immunoglobulin levels. One should bear in mind that in-born immune deficiencies are more prevalent among patients with autoimmune diseases, and many authors suggest that immune deficiencies themselves are the main cause for the development of autoimmune disturbances. In order to achieve optimum results, the treatment of such patients should be based on joint efforts of a wide range of specialists, including clinical immunologists, endocrinologists, rheumatologists, nephrologists, internal medicine experts, pediatrics, and hematologists.

\section{Conclusions}

CVID is the most common immune deficiency. The delay of diagnosis in Bulgaria is approximately 9.5 years. Approximately, 20\% of CVID patients present with additional autoimmune disease, which is diagnosed before, after, or concomitantly with the immune deficiency. The early diagnosis and treatment of CVID and the accompanying autoimmune diseases could prevent complications and improve quality of life of a patient. Rare diseases experts' centers and especially, primary immune deficiencies specialists should take active part in the diagnosis and treatment of such patients, working together through an international network of primary immune deficiencies.

\section{The authors declare no conflict of interest.}

\section{References}

1. Gathmann B, Binder N, Ehl S, et al. (2012): The European internet-based patient and research database for primary immunodeficiencies: update 2011. Clin Exp Immunol 167: 479-491.

2. Bousfiha A, Jeddane L, Capucine Picard C, et al. (2017): The 2017 IUIS Phenotypic Classification for Primary Immunodeficiencies. J Clin Immunol 38: 129-143.

3. Cunningham-Rundles C (2012): The many faces of common variable immunodeficiency. Hematology Am Soc Hematol Educ Program 2012: 301-305.

4. Daniels JA, Lederman HM, Maitra A, Montgomery EA (2007): Gastrointestinal tract pathology in patients with common variable immunodeficiency (CVID): a clinicopathologic study and review. Am J Surg Pathol 31: 1800-1812.

5. Agarwal S, Mayer L (2009): Pathogenesis and treatment of gastrointestinal disease in antibody deficiency syndromes. J Allergy Clin Immunol 124: 658-664.

6. Grimbacher B, Hutloff A, Schlesier M, et al. (2003): Homozygous loss of ICOS is associated with adult-onset common variable immunodeficiency. Nat Immunol 4: 261-268.
7. Schaffer AA, Salzer U, Hammarstrom L, Grimbacher B (2007): Deconstructing common variable immunodeficiency by genetic analysis. Curr Opin Genet Dev 17: 201-212.

8. van Zelm MC, Smet J, Adams B, et al. (2010): CD81 gene defect in humans disrupts CD19 complex formation and leads to antibody deficiency. J Clin Invest 120: 1265-1274.

9. Thiel J, Kimmig L, Salzer U, et al. (2012): Genetic CD21 deficiency is associated with hypogammaglobulinemia. J Allergy Clin Immunol 129: 801.e6-810.e6.

10. Kuijpers TW, Bende RJ, Baars PA, et al (2010): CD20 deficiency in humans results in impaired $\mathrm{T}$ cell independent antibody responses. J Clin Investig 120: 214-222.

11. Alangari A, Alsultan A, Adly N, et al. (2012): LPS-responsive beige-like anchor (LRBA) gene mutation in a family with inflammatory bowel disease and combined immunodeficiency. J Allergy Clin Immunol 130: 481.e2-488.e2.

12. Ombrello MJ, Remmers EF, Sun G, et al. (2012): Cold urticaria, immunodeficiency, and autoimmunity related to PLCG2 deletions. N Engl J Med 366: 330-338.

13. Wang HY, Ma CA, Zhao Y, et al. (2013): Antibody deficiency associated with an inherited autosomal dominant mutation in TWEAK. Proc Natl Acad Sci USA 110: 5127-5132.

14. Shi CS, Wang F, Tong A, et al. (2016): NFKB2 mutation in common variable immunodeficiency and isolated adrenocorticotropic hormone deficiency. A case report and review of literature. Medicine 95: 40.

15. Pivonello R, de Bellis A, Faggiano A, et al. (2003): Central diabetes insipidus and autoimmunity; Relationship between the occurrence of antibodies to arginin vasopressin-secreting cells and clinical, immunological and radiological features in a large cohort of patients with central diabetes insipidus of known and unknown etiology. J Clin Endocrin Metabol 88: 1629-1636.

16. Mowat AM (2003): Coeliac disease - a meeting point for genetics, immunology, and protein chemistry. Lancet 361 : 1290-1292.

17. Bellastella G, Bizzarro A, Aitella E, et al. (2015): Pregnancy may favour the development of severe autoimmune central diabetes insipidus in women with vasopressin cell antibodies: description of two cases. Eur J Endocrinol 172: K11-K17.

18. Cunningham-Rundles C, Bodian C (1999): Common variable immunodeficiency: clinical and immunological features of 248 patients. Clin Immunol 92: 34-48.

19. Giorgio F, Principi M, Losurdo G, et al (2015): Seronegative celiac disease and immunoglobulin deficiency: where to look in the submerged iceberg? Nutrients 7: 7486-7504.

20. Megías MC, Matei AM, Albarran OG, Lopez GP (2012): Partial central diabetes insipidus in patient with common variable immunodeficiency. BMJ Case Rep 2012: bcr1120115067.

21. Younes JS, Second EA (2002): Panhypopituitarism in a child with common variable immunodeficiency. Ann Allergy Asthma Immunol 89: 322-325.

22. Delvecchio M, De Bellis A, De Mattia D, et al. (2009): Growth hormone deficiency and antipituitary antibodies in a patient with common variable immunodeficiency. J Endocrinol Invest 32: 637-640.

23. Tovo PA, Lala R, Martino S, et al. (1991): Isolated adrenocorticotropic hormone deficiency associated with common variable immunodeficiency. Eur J Pediatr 150: 400-402.

24. Thuc-Uyen Nguyen J, Green A, Michael R, et al. (2016): Neurologic Complications of Common Variable Immunodeficiency. J Clin Immunol 36: 793-800. 